\title{
ULRICH SIEG
}

Jüdische Intellektuelle im Ersten Weltkrieg 



\title{
$\underline{\text { ULRICH SIEG }}$
}

\section{Jüdische Intellektuelle im Ersten Weltkrieg \\ Kriegserfahrungen, weltanschauliche Debatten und kulturelle Neuentwürfe}

\author{
2., unveränderte Auflage
}

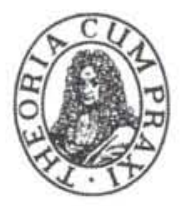

Akademie Verlag 
1. Auflage Akademie Verlag, Berlin 2001

2. Auflage Akademie Verlag, Berlin 2008

Bibliografische Information der Deutschen Nationalbibliothek

Die Deutsche Nationalbibliothek verzeichnet diese Publikation in der Deutschen Nationalbibliografie; detaillierte bibliografische Daten sind im Internet über http://dnb.d-nb.de abrufbar.

ISBN 978-3-05-004524-5

(c) Akademie Verlag GmbH, Berlin 2008

Das eingesetzte Papier ist alterungsbeständig nach DIN/ISO 9706.

Alle Rechte, insbesondere die der Übersetzung in andere Sprachen, vorbehalten. Kein Teil dieses Buches darf ohne schriftliche Genehmigung des Verlages in irgendeiner Form - durch Photokopie, Mikroverfilmung oder irgendein anderes Verfahren - reproduziert oder in eine von Maschinen, insbesondere von Datenverarbeitungsmaschinen, verwendbare Sprache übertragen oder übersetzt werden.

Einbandgestaltung: Ingo Ostermaier, Berlin Druck: Digital Printing Service, Andernach

Printed in the Federal Republic of Germany 